University of Nebraska - Lincoln

DigitalCommons@University of Nebraska - Lincoln

Faculty Publications: Department of Entomology

February 2004

piggyBac transformation of the New World screwworm, Cochliomyia hominivorax, produces multiple distinct mutant strains

M.L. Allen

A.M. Handler

US Department of Agriculture, Gainesville, U.S.A.

Dennis Berkebile

USDA-ARS, DENNIS.BERKEBILE@ars.usda.gov

S.R. Skoda

USDA-ARS

Follow this and additional works at: https://digitalcommons.unl.edu/entomologyfacpub

Part of the Entomology Commons

Allen, M.L.; Handler, A.M.; Berkebile, Dennis; and Skoda, S.R., "piggyBac transformation of the New World screwworm, Cochliomyia hominivorax, produces multiple distinct mutant strains" (2004). Faculty Publications: Department of Entomology. 29.

https://digitalcommons.unl.edu/entomologyfacpub/29

This Article is brought to you for free and open access by the Entomology, Department of at DigitalCommons@University of Nebraska - Lincoln. It has been accepted for inclusion in Faculty Publications: Department of Entomology by an authorized administrator of DigitalCommons@University of Nebraska - Lincoln. 
Medical and Veterinary Entomology (2004) 18, 1-9

\title{
piggyBac transformation of the New World screwworm, Cochliomyia hominivorax, produces multiple distinct mutant strains
}

\author{
M. L. ALLEN, A. M. HANDLER* , D. R. BERKEBILE and S. R. SKODA \\ Midwest Livestock Insects Laboratory, US Department of Agriculture, Lincoln and *Center for Medical and Veterinary \\ Entomology, US Department of Agriculture, Gainesville, U.S.A.
}

\begin{abstract}
Sterile insect technique (SIT) programs are designed to eradicate pest species by releasing mass-reared, sterile insects into an infested area. The first major implementation of SIT was the New World Screwworm Eradication Program, which successfully eliminated the New World screwworm (NWS), Cochliomyia hominivorax (Coquerel) (Diptera: Calliphoridae), from the Continental US, Mexico and much of Central America. Ionizing radiation is currently used for sterilization, but transgenic insect techniques could replace this method, providing a safer, more cost-effective alternative. Genetic transformation methods have been demonstrated in NWS, and verified by Southern blot hybridization, PCR and sequencing of element insertion junctions. A lethal insertional mutation and enhancer detection-like phenotypic expression variations are presented and discussed. In addition to supporting the eradication efforts, transformation methods offer potential means to identify genes and examine gene function in NWS.
\end{abstract}

Key words. Cochliomyia hominivorax, green fluorescent protein, piggyBac, screwworm, sterile insect technique (SIT), transformation, transgenic insect

\section{Introduction}

The New World screwworm (NWS), Cochliomyia hominivorax (Coquerel), was once a costly pest of livestock and other warm-blooded animals, including humans, in the US and Mexico. The insect damages its host by feeding as a maggot on living tissue at a wound site. NWS has been successfully eradicated from the entire North American continent through a multinational programme; this eradication programme was the first implementation of the sterile insect technique (SIT). SIT theory states that a wild population can be eliminated if the pest insect can be economically mass-reared, effectively sterilized and dispersed at a sufficiently high ratio of sterile to wild males, there is no

Correspondence: Margaret L. Allen, Midwest Livestock Insects Laboratory, US Department of Agriculture, Agricultural Research Service, 305 Plant Industry Building, University of Nebraska East Campus, Lincoln, NE 68583, U.S.A. E-mail: mallen2@unl.edu immigration and the sterilized insects are able to mate competitively (Knipling, 1955). The annual estimated benefits of NWS eradication to livestock producers in the US and Mexico exceed \$1 billion (Wyss \& Galvin, 1996) (http://www.aphis.usda.gov/bad/refbook2000/Screwworm.pdf). NWS are prevented from reinfesting North America by the ongoing release of sterile adult flies at the current barrier zone in Panama. Sterile flies for release are produced by irradiation in a highly secure mass-rearing facility in Tuxtla Gutierrez, Mexico (Wyss, 2000).

Transposable element-mediated insect transformation has been proposed as a means to improve and augment SIT programmes (Heinrich \& Scott, 2000; Alphey, 2002; Handler, 2002; Horn \& Wimmer, 2003). Applications for insect transformation include: unambiguous marking of released insects; restrictive rearing conditions (diet-suppressed conditional lethal); genetic sexing strain through female lethal selection (Heinrich \& Scott, 2000; Horn \& Wimmer, 2003), preferably at the larval stage; and genetically sterile insects, preferably males. 
Unambiguously marked strains of insects used in a SIT programme would benefit eradication efforts by clearly and quickly identifying production facility-reared vs. wild insects in cases of outbreaks or expanded releases. NWS is still indigenous to South America and the Caribbean, and if world-wide eradication of NWS is pursued, monitoring of progress would be facilitated by simple and quick identification of mass-reared insects. The current climate of world concern over bioterrorism demands that any outbreaks of NWS in non-endemic regions be rapidly evaluated for origination of infestation. Additionally, mass-reared screwworms capable of surviving only under specific permissive dietary conditions in artificial rearing would add to the measures of biosecurity, by eliminating survival of any insects that escape the rearing facility.

Any method of identifying and removing female screwworms from the insects reared for release would be of great value to the eradication process. If adult females were removed prior to release, more males (the effective sex in SIT) could be irradiated and packaged. If females could be identified and removed from rearing early in development, the cost of feeding the growing larvae in mass rearing could be greatly reduced. Also, the removal of females from the released population would reduce the expense for irradiation, as males are sterilized at a lower dose of radiation than females (LaChance et al., 1967).

An ancillary use for insect transformation is the identification and testing, in vivo, of functional genes. The vast majority of insect species, including economically and medically important insects, will not be candidates for genomic sequencing in the near future. Therefore, if an insect such as NWS is amenable to genetic manipulation by transformation, position effects of the presumably random insertions of markers may provide interesting and useful genetic information (Bellen et al., 1989).

Here we describe the first transformation and establishment of stable colonies of transgenic NWS, C. hominivorax. We also discuss the unique characteristics of several distinct transgenic NWS strains, and their implications.

\section{Materials and methods}

\section{Insect strains and rearing}

Transformed $C$. hominivorax were derived from the P95 strain, which is the current strain used in the SIT programme. Insects were reared according to USDA-ARS and APHIS established protocols (Melvin \& Bushland, 1936; Taylor et al., 1991), modified somewhat to accommodate rearing of small numbers of insects. Other NWS strains used as controls were $\mathrm{J} 1, \mathrm{~J} 5$ and $\mathrm{J} 14$, colonies established in 1998 (J1) and 2002 (J5, J14) from specimens collected in Jamaica. Other species used in PCR studies were collected locally (Lincoln, Nebraska, U.S.A.); colonies were maintained temporarily in the Biosecure Facility in Lincoln and reared according to standard protocols.

\section{Plasmids}

A solution of $250 \mu \mathrm{g} / \mathrm{mL}$ helper plasmid (transposaseencoding) phsp-pBac, and $250 \mu \mathrm{g} / \mathrm{mL}$ vector pB[PUbnlsEGFP] (Handler \& Harrell et al., 1999, 2001a) in injection buffer was used for all microinjections. Plasmids were suspended in $6.25 \mathrm{~mm}$ Bis-Tris buffer with blue indicator dye. The $\mathrm{pB}[\mathrm{PUbnlsEGFP]}$ vector has the humanized enhanced green fluorescent protein (EGFP) variant gene (Clontech, Palo Alto, CA) under the regulation of the Drosophila melanogaster Meigen polyubiquitin promoter (Lee et al., 1988), which is normally active in all tissues throughout development. It is further linked to the SV40 T-antigen nuclear localizing sequence (nls) (Lanford et al., 1986).

\section{Microinjection}

Adult colonies of NWS were provided with substrate (raw ground beef) on which females deposited eggs for 15 min. Eggs were washed immediately with $1 \% \mathrm{NaOH}$ solution to separate the masses (Berkebile \& Skoda, 2002), and arranged on double-sided adhesive tape. The eggs were not dechorionated by this treatment, but the chorion was softened. Standard procedures for both D. melanogaster (Rubin \& Spradling, 1982) and Aedes aegypti (Linaeus) (Morris, 1997) include injecting under oil; however, other insects have been transformed successfully without this step (Allen et al., 2001). NWS embryos were microinjected with plasmid solution at the posterior end, without oil, using bevelled borosilicate needles and an Eppendorf Transjector $5246^{\mathrm{TM}}$ system. Although a $37^{\circ} \mathrm{C}$ heat shock is normally applied to embryos after injection when using the piggyBac helper plasmid (Handler etal., 1998; Handler \& Harrell, 1999), the NWS were reared at $37^{\circ} \mathrm{C}$, so heat shock was unnecessary. All surviving injected insects were individually mated to wild-type P95 flies.

\section{Screening and photography}

Insects were screened with a Leica MZFLIII ${ }^{\mathrm{TM}}$ fluorescence stereomicroscope using the GFP2 filter set. The most efficient stage to screen was the crawler stage (fully mature third instars). Fluorescence could not be detected in the pupal or adult stage without dissection. Although fluorescence was visible in transgenic eggs, it was more apparent when the embryo was ready to hatch, but not in all strains. Removal of larvae from rearing medium prior to the crawler stage was often lethal. The crawler stage occurred after Day 5 of incubation, and once the larvae exited the rearing medium they pupated within $8 \mathrm{~h}$. Thus, the screening step was restricted to a single day. Photographs were obtained using a Roper CoolSnap $\mathrm{cf}^{\mathrm{TM}}$ digital camera (Roper Scientific Inc., Tucson, AZ) accompanying Roper software, and Adobe Photoshop 6.0 ${ }^{\mathrm{TM}}$ software (Adobe Systems Inc., San José, CA). 
Genomic Southern blot hybridization

Genomic DNA (gDNA) was extracted from washed pupae using the Promega Wizard ${ }^{\mathrm{TM}}$ kit (Promega, Madison, WI), according to instructions provided by the manufacturer, incorporating a Proteinase $\mathrm{K}$ overnight digestion step. The gDNA specimens were digested with the following enzymes: HindIII, SalI, NotI and BglII, and size-fractionated on agarose gels, then transferred to a nylon membrane using standard procedures (Sambrook etal., 1989). A $580 \mathrm{bp}$ product was PCR amplified from the vector plasmid pB[PUbnlsEGFP], $3^{\prime}$ piggyBac end (primers 1514F 5'-TGTTTTGACGGACCCCTTAC- $3^{\prime}$ and 2094R 5'-CCAGAAACAACTTTGGCACA-3'). PCR was performed using $\mathrm{ABI}$ AmpliTaq Gold ${ }^{\mathrm{TM}}$ at the following conditions: $95^{\circ} \mathrm{C} 5 \mathrm{~min}\left(95^{\circ} \mathrm{C} 15 \mathrm{~s}, 55^{\circ} \mathrm{C} 15 \mathrm{~s}, 72^{\circ} \mathrm{C} 50 \mathrm{~s}\right)$ 35 times, $72^{\circ} \mathrm{C} 7 \mathrm{~min}, 4^{\circ} \mathrm{C}$. The amplicon was radioactively labelled using Amersham rediPrimeII ${ }^{\mathrm{TM}}$ random prime kit (Amersham Biosciences, Piscataway, NJ), and used to probe the genomic blot.

\section{$P C R$}

For inverse PCR, specimens of gDNA (approximately $2 \mathrm{mg} / \mathrm{sample}$ ) were digested with Sau3AI restriction endonuclease for 16-20 h. Half of the digested sample was cleaned (Zymo Research DNA Clean \& Concentrator- $5^{\mathrm{TM}}$, Orange, $\mathrm{CA}$ ), and $1 / 50$ th of the material was ligated in a $40 \mu \mathrm{L}$ reaction volume using T4 DNA ligase, again for 16-20 h. The ligations $(2 \mu \mathrm{L}$ used as template) were subjected to PCR amplification, using primers (in outward orientation) designed from the ends of the piggyBac element, under conditions recommended in the Expand Long Template PCR system (Roche Diagnostics Corporation, Indianapolis, IN) instructions: $93^{\circ} \mathrm{C} 2 \mathrm{~min}\left(94^{\circ} \mathrm{C} 10 \mathrm{~s}, 55^{\circ} \mathrm{C} 30 \mathrm{~s}, 68^{\circ} \mathrm{C} 6 \mathrm{~min}\right)$ 10 times $\left(94^{\circ} \mathrm{C} 10 \mathrm{~s}, 55^{\circ} \mathrm{C} 30 \mathrm{~s}, 68^{\circ} \mathrm{C} 6 \mathrm{~min}+20 \mathrm{~s} /\right.$ cycle $) 25$ times, $72^{\circ} \mathrm{C} 7 \mathrm{~min}, 4^{\circ} \mathrm{C}$. Nested primers were designed using Primer3 (Rozen \& Skaletsky, 2000) for both the $5^{\prime}$ and $3^{\prime}$ ends of the piggyBac vector ( $5^{\prime}$ external primers used for first round PCR: 162R 5'-CACGCGGTCGTTATAGTTCA-3' and 357F 5'-TCCTCTCTGC TCTTCTGCAA-3'; $5^{\prime}$ internal primers used for second round PCR: 61R 5'-ACGGATT CGCG CTATTTAGA- $3^{\prime}$ and 380F $5^{\prime}$-GATGACGAGCTT GTTGG TGA-3'; $3^{\prime}$ external primers used for first round PCR: 1648R 5'-CCACTCCGCCTTTAGTTTGA-3' and 2099F 5'TGTGCCAAAGTTGTTTCTG-3'; $3^{\prime}$ internal primers used for second round PCR: 1514R 5'-GTAAG GGGTCCGTCAAAACA- $3^{\prime}$ and 2385F $5^{\prime}$-CCTCGATATACAGACCGATA$\left.3^{\prime}\right)$. Amplicons were excised from agarose gels after brief visualization, and gel purified (Qiagen MinElute ${ }^{\mathrm{TM}}$, Valencia, CA). Some amplicons (approximately $1 \mathrm{ng}$ template) were reamplified using nested primers and Applied Biosystems (Foster City, CA) AmpliTaq Gold ${ }^{\mathrm{TM}}$ PCR system (ABI) at the following conditions: $95^{\circ} \mathrm{C} 5 \mathrm{~min}\left(95^{\circ} \mathrm{C} 15 \mathrm{~s}, 55^{\circ} \mathrm{C} 15 \mathrm{~s}, 72^{\circ} \mathrm{C} 50 \mathrm{~s}\right) 35$ times, $72^{\circ} \mathrm{C} 7 \mathrm{~min}, 4^{\circ} \mathrm{C}$. Amplicons were sequenced by the University of Nebraska, Lincoln Genomics Core Facility, and compared to the known piggy Bac terminal sequences and other published genomic sequences using NCBI BLAST programmes (Altschul et al., 1997).

Specimens of gDNA from NWS strains P95, J5 and J14, and gDNA extracted (as above) from Cochliomyia macellaria (F.) and Lucilia sp. were digested with NotI restriction endonuclease. Primers were designed from the putative NWS genomic sequences, obtained by PCR amplifications described above, for insertion sites from two transgenic lines. These primers were designed to amplify across the TTAA piggyBac insertion sites (GIZA 33F 5'-TCTTCT GATCTTGTTTCCA-3', GIZA 366R 5'-AACGTTTCCT GCATAAATATCGT-3'; CLAY 53F 5'-AAATCGTCACGACTCCTTGC-3', CLAY 241R 5'-AGTTGTGTCCTT GCGTTTG-3'). PCR was performed using ABI AmpliTaq Gold $^{\mathrm{TM}}$, for 35 cycles as above.

\section{Results}

Injection and strain establishment

A total of 2180 injected C. hominivorax (strain P95) embryos yielded a relatively low number of 49 adults (Table 1). Combined factors, including injection trauma

Table 1. Microinjection of Cochliomyia hominivorax embryos

\begin{tabular}{|c|c|c|c|c|c|c|c|c|c|}
\hline Week & $\begin{array}{l}\text { Total } \\
\text { embryos } \\
\text { injected }\end{array}$ & $\begin{array}{l}\text { Total } \\
\text { pupae } \\
\text { collected }\end{array}$ & $\begin{array}{l}\text { Percent } \\
\text { pupated }\end{array}$ & $\begin{array}{l}\text { Total } \\
\text { adult } \\
\text { survival }\end{array}$ & $\begin{array}{l}\text { Adults } \\
\mathrm{M} / \mathrm{F}\end{array}$ & $\begin{array}{l}\text { Fertile } \\
\text { adults } \\
\mathrm{M} / \mathrm{F}\end{array}$ & $\begin{array}{l}\text { G1* } \\
\text { offspring } \\
\text { screened }\end{array}$ & $\begin{array}{l}\text { Transgenic } \\
\text { adults } \\
\mathrm{M} / \mathrm{F}\end{array}$ & $\begin{array}{l}\text { Transformation } \\
\text { frequency }(\%) \\
\text { (transgenic/fertile) }\end{array}$ \\
\hline 1 & 260 & 20 & 7.7 & 3 & $3 / 0$ & 0 & 0 & & - \\
\hline 2 & 898 & 32 & 3.6 & 12 & $5 / 7$ & $5 / 0$ & 1500 & 0 & - \\
\hline 3 & 710 & 89 & 12.5 & 31 & $19 / 12$ & $11 / 3$ & 2700 & $1 / 1$ & 14.29 \\
\hline 4 & 312 & 14 & 4.5 & 3 & $2 / 1$ & $2 / 1$ & 600 & $1 / 0$ & 33.33 \\
\hline Total & 2180 & 155 & 7.1 & 49 & $29 / 20$ & $18 / 4$ & 4800 & $2 / 1$ & 13.64 \\
\hline$\%$ of injected: & & & & 2.2 & & 1.0 & & & \\
\hline$\%$ of pupae: & & & & 31.6 & & 14.2 & & & \\
\hline$\%$ of adults: & & & & & & 44.9 & & & \\
\hline
\end{tabular}

*Estimate based on 100 eggs per mass.

$\mathrm{M}=$ male, $\mathrm{F}=$ female 
and decreased larval density in rearing medium, contributed to this relatively low survival. However, of the 22 adults that were successfully mated, three yielded transgenic offspring. Both of the transgenic matings in week 3 produced larvae positive for green fluorescence (EGFP+), 12 larvae from one mating and four from the other. In contrast, the week 4 transgenic mating produced more than $50 \mathrm{EGFP}+$ maggots. The former were individually outcrossed to P95 (wild-type) adults, but the latter were outcrossed in pools. Offspring of the two transformationpositive adults produced in week 3 were identified with the letters $\mathrm{X}$ and $\mathrm{Y}$, and those of the transformation-positive adult produced in week 4 were designated as $\mathrm{Z}$. The $\mathrm{Z}$ transgenic offspring appeared phenotypically homogenous, with fluorescence in the gut and salivary glands. The $\mathrm{X}$ progeny were less homogenous, but mainly characterized by fluorescence detectable in the salivary glands and in cells just under the cuticle. The Y progeny were the least homogenous, with some showing expression near the cuticle, the gut, salivary glands and the fat body, in varying combinations. Several generations of outcrosses resulted in eight stable colonies, representing seven distinct phenotypes, designated as: CL*X, CLAY, COTY, FOLY, GARY, GIZA and SUEZ (* = I or O). Letters were added to the $(\mathrm{X}, \mathrm{Y}, \mathrm{Z})$ labels to indicate the main expression pattern $(\mathrm{C}=$ cuticle, $\mathrm{F}=$ fat body, $\mathrm{G}=$ gut, $\mathrm{S}=$ spiracles $)$ and to form pronounceable names.

The characteristics of the strains selected as putative single transgene insertions are shown in Fig. 1. CLIX and CLOX fluoresce in the salivary glands and in cells near the cuticle. Cuticular expression is most distinct at intersegmental areas, but is moderately bright throughout. CLAY is characterized by very bright expression under the entire cuticle, in the salivary glands, and pharyngeal filter. COTY fluoresces in both the salivary glands and at the intersegmental areas of the cuticle, but with much less intensity than CLI/OX or CLAY. The FOLY strain exhibits fluorescence in what appears to be fat body tissue and in the gut. GARY expresses fluorescence in the antennomaxillary palpi, the pharyngeal filter, salivary glands and in a central portion of the larval gut. GIZA expresses fluorescent protein in the salivary glands and a large segment of gut, and SUEZ expresses only around the anterior and posterior spiracles. Each strain has been stable for over 16 generations. Each appears to be homozygous, based on no wild-type individuals found in screened offspring for more than eight generations, except for the GIZA strain, which is lethal in the homozygous state (Table 2).

The GIZA strain was observed to produce substantial numbers of wild-type individuals every generation when all wild-types were discarded each generation. This led to our hypothesis that the piggyBac insert interrupted a vital gene, resulting in death of the homozygous transgenic offspring. Screened larvae were counted and compared to expected Mendelian ratios for a lethal gene mutation, and support the hypothesis of a lethal insertion (Table 2).

\section{Molecular analysis}

Southern blot analysis confirmed integration of the piggyBac vector cassette into the genome of the transgenic strains CLAY, CLIX, CLOX, COTY, GARY and GIZA (Fig. 2). Strains CLAY, CLIX, COTY, GIZA and GARY each contain a single copy of the transgene, whereas CLOX contains a duplicate insertion.

Inverse PCR was used to amplify the genomic sequence surrounding the piggyBac insertion site (Fig.3). All sequences revealed the duplicated TTAA insertion site expected from piggyBac-mediated integration (Elick et al., 1996). Junction sequences from both $5^{\prime}$ and $3^{\prime}$ ends were obtained from strains CLAY, FOLY, GARY, GIZA and SUEZ. The putative genomic nucleotide sequences did not resemble one another or any other genomic sequences other than random $20 \mathrm{bp}$ homologies (NCBI BLAST standard nucleotide comparisons); however, translated protein comparisons (BLASTx) of the sequences resulted in some homology. A total of 131 putative translated residues of GIZA sequence were $45 \%$ identical and $61 \%$ positive for an An. gambiae protein EAA12189 (gi: 21300044), and 42\% identical and $63 \%$ positive for D. melanogaster CG6976-PB (gi: 24582545) and CG6976-PD (gi: 24582551), an unconventional myosin VII-like protein. A total of 132 putative translated residues of the CLAY sequence were $80 \%$ identical and $86 \%$ positive for D. melanogaster protein CG3996-PA (gi: 24645646) and 79\% identical and 93\% positive for An. gambiae protein EAA14637 (gi: 21302492).

If the amplified sequence surrounding the piggy Bac insertion site is genomic NWS DNA, then primers based on sequences from each side $\left(5^{\prime}\right.$ and $\left.3^{\prime}\right)$ of a single insertion should amplify a predictable length of genomic DNA from wild-type NWS. Furthermore, if the insertion site is within a genomic region conserved between fly species, amplification of a similar length of genomic DNA might be obtained from related species. Using the NWS genomic sequences identified by inverse PCR, primers were designed that span the piggyBac insertion sites for the transgenic NWS strains GIZA and CLAY. These primers were used to amplify genomic DNA from wild-type NWS strains P95, J5 and J14 (two strains developed from recently collected Jamaican specimens), and two closely related blow flies, the secondary screwworm $C$. macellaria and a species of Lucilia (Phaenicia) found in Lincoln, Nebraska (U.S.A.). The GIZA primers amplified appropriately sized DNA fragments from all gDNA specimens, less efficiently in the non-conspecifics, and the CLAY primers only amplified from NWS specimens (Fig. 4).

\section{Discussion}

This is the first report of transformation of New World screwworm, and we have established eight stable colonies. The transformations have been confirmed by molecular analyses. 

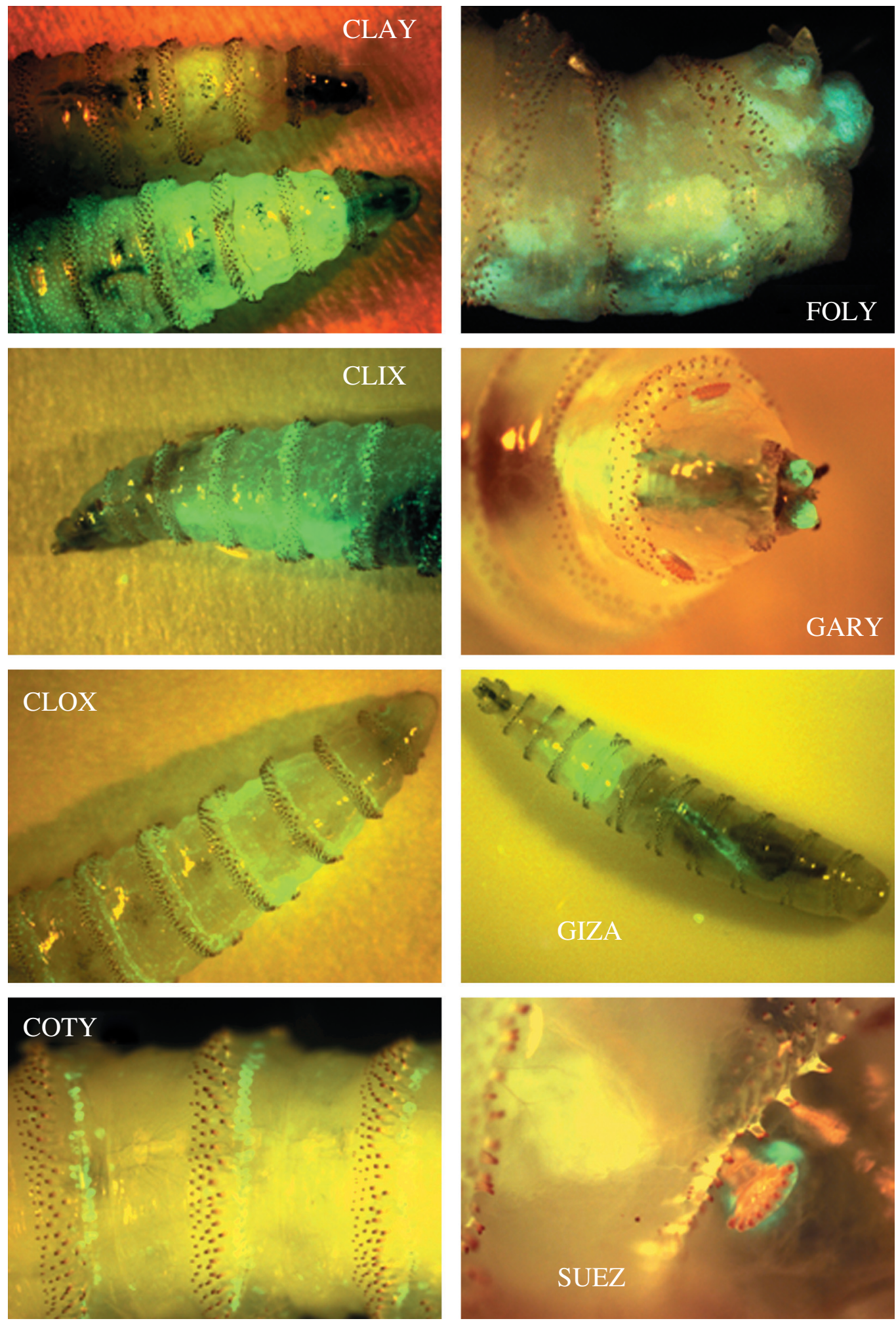

Fig. 1. Transgenic strains of Cochliomyia hominivorax, the New World screwworm (NWS). 
Table 2. Verification of lethal transgenic insertion (GIZA)

\begin{tabular}{llllll}
\hline & \multicolumn{2}{l}{ Observed } & & \multicolumn{2}{c}{ Expected 2:1 } \\
\cline { 2 - 3 } Count & GFP + & wt & & GFP + & wt \\
\hline 1 & 107 & 43 & & 100 & 50 \\
2 & 79 & 46 & 83 & 42 \\
3 & 502 & 218 & 480 & 240 \\
4 & 303 & 148 & & 301 & 150 \\
Total & 991 & 455 & & 964 & 482 \\
$\chi^{2}(P>0.25)$ & 0.628 & 0.323 & & \\
\hline
\end{tabular}

$\mathrm{wt}=$ wild type.

The transposable element piggyBac has been used to genetically transform several insect species of economic importance. These include three species (of three genera) of fruit flies (Family Tephritidae) (Handler \& Harrell, 1998, 2001c; Handler \& McCombs, 2000), two lepidopterans (the pink bollworm and silkworm) (Peloquin etal., 2000;
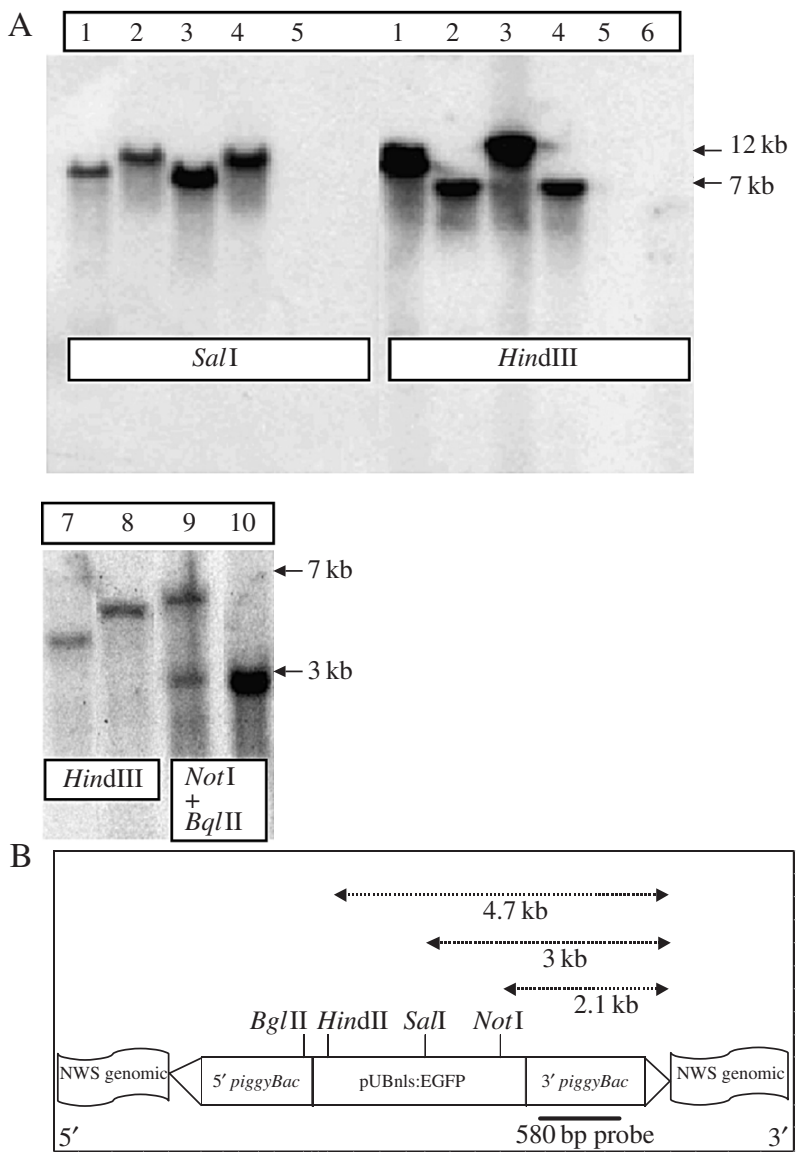

Fig. 2. (A) Hybridization of vector probe to genomic Southern blots of restriction enzyme digested transgenic NWS. Lanes: 1, CLIX; 2, 4, GIZA; 3, 10, GARY; 5, P95 (wild type); 6, J1 (wild type), 7, CLAY, 8, COTY, 9, CLOX. (B) Diagrammatic representation of $\mathrm{pB}[\mathrm{PUbnlsEGFP}]$ in transgenic NWS, showing location of restriction sites and probe. Single insertions should give single hybridization products larger than the vector lengths shown.
Tamura etal., 2000), three mosquitoes (Grossman etal., 2001; Kokoza etal., 2001; Lobo et al., 2002; Perera etal., 2002), the house fly (Hediger et al., 2001), the sheep blowfly (Heinrich et al., 2002), the red flour beetle (Berghammer et al., 1999) and a sawfly (Sumitani et al., 2003). The most closely related insect to have been transformed in the manner described here is Lucilia cuprina (Weidemann), the sheep blowfly (Heinrich et al., 2002). The transformation frequency reported for L. cuprina was lower than in NWS, but the number of surviving injected insects was much higher than our results. Transgenics of both species express EGFP in the embryo and larval stages, and in adult ovaries (data not shown). A great concern with NWS was the rapid embryonic development. The embryo hatches after $9 \mathrm{~h}$ at $37^{\circ} \mathrm{C}$ (standard mass-rearing protocol), and transformation protocol dictates that the plasmids are delivered to the developing embryo prior to cellularization of the syncitial blastoderm. Therefore, every effort was made to inject embryos as early as possible. We believe our injection technique improved over time (Table 1), as the number of $\mathrm{GFP}+$ first generation transgenics was much higher $(>50)$ in the final successful injection, $Z$. This leads us to speculate that an early germ line nucleus was transformed, which successfully replicated into many gametes. The $\mathrm{X}$ and $\mathrm{Y}$ transformation events may have occurred later in development, resulting in fewer sibling transformants.

The variation in expression patterns made it possible to isolate unique phenotypes associated with single transgene inserts that were amenable to inverse PCR and sequencing. Each of the insertions identified resulted in the canonical piggyBac TTAA integration specificity. Examination of the fluorescence expression can provide clues about the insertion site. Expression in cells near the cuticle appeared in four of the eight transgenic NWS strains, and was also described in PUbnlsEGFP transgenic Anastrepha suspensa (Loew) (Handler \& Harrell, 2001b). This leads us to speculate that epidermal fluorescence may be a default expression pattern for PUbnlsEGFP in larval non-drosophilid dipterans. In adult tephritids (Handler \& Harrell, 2001b) and drosophilids (Handler \& Harrell, 1999) distinct fluorescence was noted in the thoracic muscles, but the NWS adult's opaque cuticle made observation of fluorescence in live specimens impossible, and although dissected flight muscles of transformed specimens appeared fluorescent, similar fluorescence was observed in wild-type individuals (data not shown). Position effects will be analysed as more information about the insertion site characteristics becomes available. For future NWS transformations it would be useful to identify promoters expected to actively express in the embryonic and/or larval stages to facilitate transgenic screening.

The lethal insert in the GIZA strain was clearly validated by the ratios of GFP + to wild-type larvae produced repeatedly after selecting only GFP + individuals at every generation (Table 2). Although further sequencing will be required to identify and characterize the insertion site, the similarity of the genomic sequence surrounding the insertion site to a myosin gene also supports the assumption that the vector insert produced a lethal mutation. Myo28B1 in D. melanogaster is a 


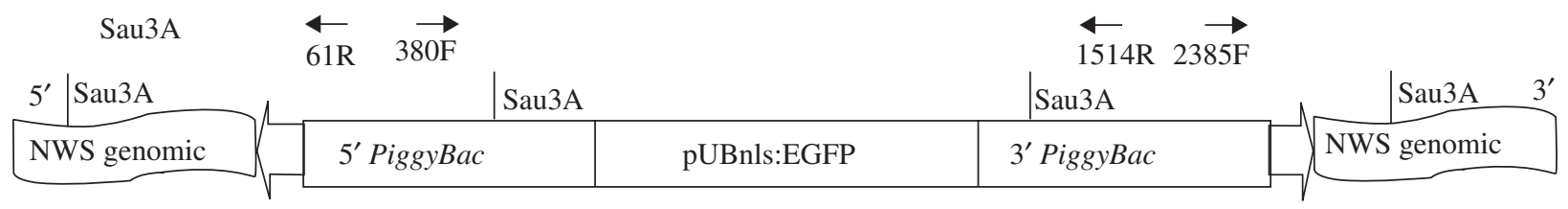

Sequence Alignments, New World screwworm (NWS) piggyBac junctions:

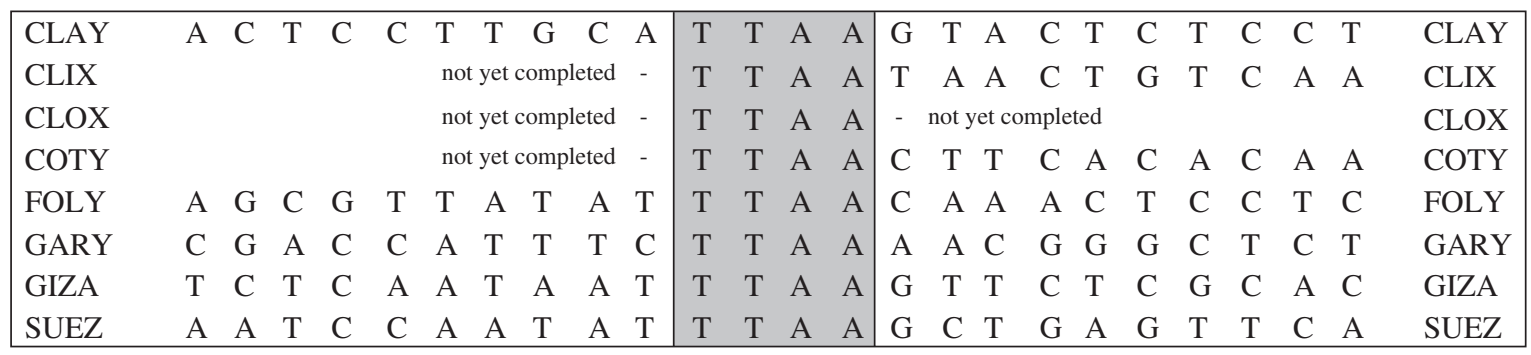

PRIMERS: $\quad$ 61R: ACG GAT TCG CGC TAT TTA GA

380F : GAT GAC GAG CTT GTT GGT GA

1514R : GTA AGG GGT CCG TCA AAA CA

2385F : CCT CGA TAT ACA GAC CGA TA

Fig. 3. Inverse PCR model used to identify sequences of piggyBac insertion sites in transgenic NWS strains.

single copy gene that encodes four isoforms of an unconventional myosin motor (FlyBase CG6976) (Yamashita etal., 2000). If this myosin motor is a component of basic cellular functions such as vesicle transport or actin organization, as has been suggested (Titus, 1999; Tuxworth \& Titus, 2000), then insertional mutation would logically be lethal.

The genomic sequences identified through inverse PCR showed varying degrees of homology with closely related blowfly species. Clearly in the two primer sets tested, interspecies variation in homology was present (Fig. 4). Based on the translated BLASTx sequence homologies we predicted that both primer sets would amplify from closely related

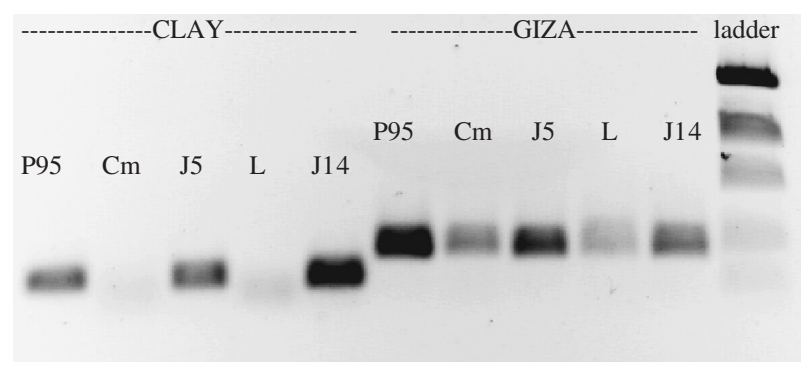

Fig. 4. Primers designed from genomic NWS junction sequences amplify appropriately from wild-type strains and other species of Calliphoridae. CLAY primers were used in lanes 1-5. GIZA primers were used in lanes 6-10. Ladder markers are (top to bottom) 2000, 1200, 800, 400 and 200 bp. Expected amplicon size for GIZA primers is $350 \mathrm{bp}$, for CLAY primers $200 \mathrm{bp}$. P95, J5 and J14 are strains of NWS (Cochliomyia hominivorax), $\mathrm{Cm}=$ C. macellaria, $\mathrm{Ph}=$ Lucilia $($ Phaenicia $)$ sp. flies. It was unexpected that the more apparently conserved (79\% identical residues) of the two translated sequences, CLAY, did not amplify products from $C$. macellaria or Lucilia. We intend to define and characterize these sequences further, and anticipate that they will be useful to identify and delineate populations of NWS.

The NWS eradication programme could benefit greatly from utilization of transgenic technology. The initial goal of producing genetically marked strains of NWS has been achieved as described here. Of the strains produced, one contains a lethal insertion, but other colonies appear vigorous. In-depth fitness comparisons of the new strains will elucidate both the appropriateness of transgenic strains for use in mass-rearing, and the potential for a genetically modified organism to persist, as it pertains to risk assessment (Ashburner et al., 1998). The production of genetically sterile strains or genetic sexing strains will depend on the availability of new transgenic tools such as inducible/repressible promoter systems, lethal (but environmentally safe) genes, and sex-specific genes and promoter systems.

In conclusion, the New World screwworm is an insect that lends itself well to piggyBac-mediated transformation. Laboratory colonies exist and rearing methods are well established in well-equipped biosecure facilities. With some effort even a single marker insertion can be utilized as an enhancer detection tool, in a similar fashion as methods used with D. melanogaster (O'Kane \& Gehring, 1987; Bellen et al., 1989, 1990). Any use of transgenic insects in SIT or other pest control programmes will require the permission and cooperation of international regulatory agencies. Both the benefits to industry and wildlife, and environmental risks 
should be thoroughly evaluated before mass release is implemented. Benefits of NWS SIT are well documented, and it is imperative that further benefits of transformation technology and associated risks be analysed carefully and rationally.

\section{Acknowledgements}

We thank the team of students and technicians at the USDA ARS MLIRU BioSecure NWS Rearing Facility, and technicians at the USDA ARS CMAVE, Alan Christensen of the UNL Biology Department, and Ron Redder and Marilyn Jepson of the UNL Genomics Core Research Facility for their excellent assistance. David Stanley and Blair Siegfried of the UNL Entomology Department, and Phil Scholl, Research Leader for the USDA ARS MLIRU, reviewed and provided helpful suggestions for the manuscript. This paper is no. 14134 of the Journal Series of the University of Nebraska Agricultural Research Division and Contribution no. 1154 of the Department of Entomology, University of Nebraska-Lincoln.

\section{References}

Allen, M.L., O'Brochta, D.A., Atkinson, P.W. \& Levesque, C.S. (2001) Stable, germ-line transformation of Culex quinquefasciatus (Diptera: Culicidae). Journal of Medical Entomology, 38, 701-10.

Alphey, L. (2002) Re-engineering the sterile insect technique. Insect Biochemistry and Molecular Biology, 32, 1243-1247.

Altschul, S.F., Madden, T.L., Schaffer, A.A., Zhang, J., Zhang, Z., Miller, W. \& Lipman, D.J. (1997) Gapped BLAST and PSIBLAST: a new generation of protein database search programs. Nucleic Acids Research, 25, 3389-402.

Ashburner, M., Hoy, M.A. \& Peloquin, J.J. (1998) Prospects for the genetic transformation of arthropods. Insect Molecular Biology, 7, 201-213.

Bellen, H.J., O'Kane, C.J., Wilson, C., Grossniklaus, U., Pearson, R.K. \& Gehring, W.J. (1989) P-element-mediated enhancer detection: a versatile method to study development in Drosophila. Genes and Development, 3, 1288-1300.

Bellen, H.J., Wilson, C., Gibson, G., Grossniklaus, U., Pearson, R.K., O'Kane, C. \& Gehring, W.J. (1990) P-element-mediated enhancer detection allows rapid identification of developmentally regulated genes and cell specific markers in Drosophila. Journal of Physiology (Paris), 84, 33-41.

Berghammer, A.J., Klingler, M. \& Wimmer, E.A. (1999) A universal marker for transgenic insects. Nature, 402, 370-1.

Berkebile, D.R. \& Skoda, S.R. (2002) Chemicals useful for separating egg masses of the screwworm. Southwestern Entomologist, 27, 297-299.

Elick, T.A., Bauser, C.A., Principe, N.M. \& Fraser, M.J. Jr (1996) PCR analysis of insertion site specificity, transcription, and structural uniformity of the Lepidopteran transposable element IFP2 in the TN-368 cell genome. Genetica, 97, 127-39.

Grossman, G.L., Rafferty, C.S., Clayton, J.R., Stevens, T.K., Mukabayire, O. \& Benedict, M.Q. (2001) Germline transformation of the malaria vector, Anopheles gambiae, with the piggyBac transposable element. Insect Molecular Biology, 10, 597-604.
Handler, A.M. (2002) Prospects for using genetic transformation for improved SIT and new biocontrol methods. Genetica, 116, 137-149.

Handler, A.M. \& Harrell, R.A., 2nd (1999) Germline transformation of Drosophila melanogaster with the piggyBac transposon vector. Insect Molecular Biology, 8, 449-457.

Handler, A.M. \& Harrell, R.A., 2nd (2001a) Polyubiquitinregulated DsRed marker for transgenic insects. Biotechniques, 31, 820, 824-828.

Handler, A.M. \& Harrell, R.A., 2nd (2001b) Transformation of the Caribbean fruit fly, Anastrepha suspensa, with a piggyBac vector marked with polyubiquitin-regulated GFP. Insect Biochemistry and Molecular Biology, 31, 199-205.

Handler, A.M. \& Harrell, R.A., 2nd (2001c) Transformation of the Caribbean fruit fly, Anastrepha suspensa, with a piggyBac vector marked with polyubiquitin-regulated GFP. Insect Biochemistry and Molecular Biology, 31, 199-205.

Handler, A.M. \& McCombs, S.D. (2000) The piggyBac transposon mediates germ-line transformation in the Oriental fruit fly and closely related elements exist in its genome. Insect Molecular Biology, 9, 605-612.

Handler, A.M., McCombs, S.D., Fraser, M.J. \& Saul, S.H. (1998) The lepidopteran transposon vector, piggyBac, mediates germ-line transformation in the Mediterranean fruit fly. Proceedings of the National Academy of Sciences of the USA, 95, 7520-7525.

Hediger, M., Niessen, M., Wimmer, E.A., Dubendorfer, A. \& Bopp, D. (2001) Genetic transformation of the housefly Musca domestica with the lepidopteran derived transposon Piggybac. Insect Molecular Biology, 10, 113-119.

Heinrich, J.C., Li, X., Henry, R.A., Haack, N., Stringfellow, L., Heath, A.C. \& Scott, M.J. (2002) Germ-line transformation of the Australian sheep blowfly Lucilia cuprina. Insect Molecular Biology, 11, 1-10.

Heinrich, J.C. \& Scott, M.J. (2000) A repressible female-specific lethal genetic system for making transgenic insect strains suitable for a sterile-release program. Proceedings of the National Academy of Sciences of the USA, 97, 8229-8232.

Horn, C. \& Wimmer, E.A. (2003) A transgene-based, embryospecific lethality system for insect pest management. Nature Biotechnology, 21, 64-70.

Knipling, E.F. (1955) Possibilities of insect control or eradication through the use of sexually sterile males. Journal of Economic Entomology, 48, 459-462.

Kokoza, V., Ahmed, A., Wimmer, E.A. \& Raikhel, A.S. (2001) Efficient transformation of the yellow fever mosquito Aedes aegypti using the piggyBac transposable element vector $\mathrm{pBac}[3 \mathrm{xP} 3-\mathrm{EGFP}$ afm]. Insect Biochemistry and Molecular Biology, 31, 1137-1143.

LaChance, L.E., Schmidt, C.H. \& Bushland, R.C. (1967) Radiation-induced sterilization. Pest Control: Biological, Physical, and Selected Chemical Methods (ed. by W. W. Kilgore and R. L. Doutt), pp. 147-196. Academic Press, New York.

Lanford, R.E., Kanda, P. \& Kennedy, R.C. (1986) Induction of nuclear transport with a synthetic peptide homologous to the SV40 T antigen transport signal. Cell, 46, 575-82.

Lee, H.S., Simon, J.A. \& Lis, J.T. (1988) Structure and expression of ubiquitin genes of Drosophila melanogaster. Molecular and Cellular Biology, 8, 4727-4735.

Lobo, N.F., Hua-Van, A., Li, X., Nolen, B.M. \& Fraser, M.J. Jr (2002) Germ line transformation of the yellow fever mosquito, Aedes aegypti, mediated by transpositional insertion of a piggyBac vector. Insect Molecular Biology, 11, 133-139. 
Melvin, R. \& Bushland, R.C. (1936) The nutritional requirements of screwworm larvae. Journal of Economic Entomology, 33, 850-852.

Morris, A.C. (1997) Microinjection of mosquito embryos. The Molecular Biology of Insect Disease Vectors (ed. by C. B. B. J. M. Crampton and C. Louis), pp. 13-20. Chapman \& Hall, London.

O'Kane, C.J. \& Gehring, W.J. (1987) Detection in situ of genomic regulatory elements in Drosophila. Proceedings of the National Academy of Sciences of the USA, 84, 9123-9127.

Peloquin, J.J., Thibault, S.T., Staten, R. \& Miller, T.A. (2000) Germ-line transformation of pink bollworm (Lepidoptera: Gelechiidae) mediated by the piggyBac transposable element. Insect Molecular Biology, 9, 323-333.

Perera, O.P., Harrell, I.R. \& Handler, A.M. (2002) Germ-line transformation of the South American malaria vector, Anopheles albimanus, with a piggyBac/EGFP transposon vector is routine and highly efficient. Insect Molecular Biology, 11, 291-297.

Rozen, S. \& Skaletsky, H. (2000) Primer3 on the WWW for general users and for biologist programmers. Methods in Molecular Biology, 132, 365-386.

Rubin, G.M. \& Spradling, A.C. (1982) Genetic transformation of Drosophila with transposable element vectors. Science, $\mathbf{2 1 8}$, $348-53$.

Sambrook, J., Maniatis, T. \& Fritsch, E.F. (1989) Molecular Cloning: A Laboratory Manual. Cold Spring Harbor Laboratory, Cold Spring Harbor, NY.

Sumitani, M., Yamamoto, D.S., Oishi, K., Lee, J.M. \& Hatakeyama, M. (2003) Germline transformation of the sawfly, Athalia rosae
(Hymenoptera: Symphyta), mediated by a piggyBac-derived vector. Insect Biochemistry and Molecular Biology, 33, 449-58.

Tamura, T., Thibert, C. Royer, C. et al. (2000) Germline transformation of the silkworm Bombyx mori L. using a piggyBac transposon-derived vector. Nature Biotechnology, 18, $81-84$.

Taylor, D.B., Bruce, J.C. \& Garcia, R. (1991) Gelled diet for screwworm (Diptera: Calliphoridae) mass production. Journal of Economic Entomology, 84, 927-935.

Titus, M.A. (1999) A class VII unconventional myosin is required for phagocytosis. Current Biology, 9, 1297-1303.

Tuxworth, R.I. \& Titus, M.A. (2000) Unconventional myosins: anchors in the membrane traffic relay. Traffic, 1, 11-18.

Wyss, J.H. (2000) Screwworm eradication in the Americas. Annals of the New York Academy of Sciences, 916, 186-193.

Wyss, J.H. \& Galvin, T.J. (1996) Central America Regional Screwworm Eradication Program (Benefit/Cost Study). VectorBorne Pathogens: International Trade and Tropical Animal Diseases (ed. by G. Uilenberg), pp. 241-247. The New York Academy of Sciences, New York.

Yamashita, R.A., Sellers, J.R. \& Anderson, J.B. (2000) Identification and analysis of the myosin superfamily in Drosophila: a database approach. Journal of Muscle Research and Cell Motility, 21, 491-505.

Accepted 26 November 2003 